DOE Report No DOE/PC 90284-8

November 1992

Quarterly Report

for

Grant No. DE-FG22-90PC90284

entitled
DOE/PC/90284-8

DE93 007479

Utc

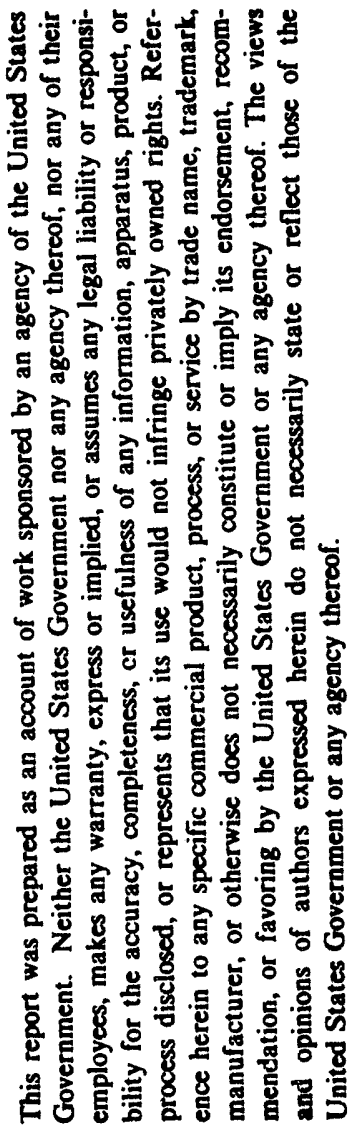

\title{
Molecular Accessibility in Solvent Swelled Coal
}

Lowell D. Kispert, Principal Investigator

Department of Chemistry

The University of Alabama

Tuscaloosa, AL 35487-0336

US/DOE Patent clearance is not required prior to the publication of this document.

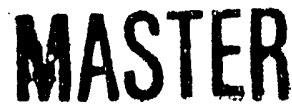




\section{PREVIOUS WORK COMPLETED}

An EPR technique developed in this lab ${ }^{1-3}$ is being used to determine the pore size and number distribution changes after swelling the coal samples with various solvents. Stable nitroxide radical spin probes of different sizes, shapes and reactivity are dissolved in an appropriate solvent, the coal sample is added to the resulting solution, stirred over night at elevated temperature, filtered, washed with a non swelling solvent to eliminate any spin probes that are not trapped in the pores and the spin concentration is measured. Comparing these spin probe measurements to DRIFT data have shown ${ }^{4}$ that the relative number distribution of acidic functionalities can be accurately predicted by the spin probe method. The spin probe method had also been used to predict ${ }^{4-5}$ the increase in elongated voids in Pittsburgh No. 8 (APCS No. 4) upon swelling with pyridine in agreement with independent SANS data. NMR relaxation data show ${ }^{3}$ that it is possible to deduce the pore (accessibility) distribution as a function of size (up to $6 \mathrm{~nm}$ ). It has also been possible by variable temperature ${ }^{1-3}$ and ENDOR measurements 6 to determine the presence of hydrogen bonding as a function of pore shape and size. The advantage of the EPR method is that it permits molecules of selected shape and size to be used as probes of accessible regions of coal, thus providing information on the importance of molecular shape.

To expand the information base on molecular accessibility in solvent swelled coal, Argonne Premium Coal Samples (APCS) were swelled in polar, basic solvents before and after moisture loss and upon air oxidation. So far studies have been reported 7,8 on the changes in pore size distribution as a function of temperature when polar basic swelling solvents are used. Additional studies employing EPR spin probe techniques performed on the breaking up of the hydrogen bonding between bedding planes 9,10 were later confirmed by magnetic resonance imaging at Argonne National Lab and the University of Illinois. 
Last quarter a paper ${ }^{11}$ was accepted in the Journal, Fuel on the micropore wall chemistry during swelling. Studies of spin probe retention with increasing spin probe polarity, provided valuable insight into the hydrogen bond cross-link density and oxygen functionality of APCS coals.

Eight Argonne Premium Coal Samples (APCS) were weathered in air and the structural and chemical changes that occurred upon swelling with toluene and pyridine were examined by our EPR spin probe method. The large structural changes were attributed to collapse of the coal structure. The results were reported at the ACS Fuel chemistry Division Annual meeting in Washington, DC., August 23-26, 1992 in the Symposium on Analytical Techniques for Characterizing Coal and Coal Conversion Products.

Finally, a paper was published 12 on our study of the changes in the molecular accessibility in solvent swelled APCS coals that had been oxidized fo, Jver a period of 6 months in ambient air with the humidity less than 50\%, and experiments on the effect of oxidation in zero percent humidity have been completed. 


\section{SUMMARY OF CURRENT ACTIVITIES}

This quarter a study of the effects of dehydration on all eight APCS coals using EPR spin probe techniques was completed. The coal samples were placed under a vacuum for several hours to achieve dehydration. Weight loss was measured, and each coal was split in to two aliquots, one to be oxidized in air ( $80 \%$ average relative humidity) and the other to be oxidized in $\mathrm{O}_{2}$. The weight of each coal sample was the monitored for a period of 35 days. Throughout this time, a sample of each coal was swelled with solvents containing EPR spin probes as previously described. Measuring the spin probe concentrations under these conditions produced data which provided insight into separating the effects of dehydration and oxidation on the coal micropore structure.

The table below shows the results of the weight measurements taken on the coal samples. \% weight loss $(V)$ refers to the weight lost after evacuation of the coal. \% weight gain $(V)$ represents the weight gained after the evacuated coal was left in air for 15 days. \% weight loss $(A)$ indicates the weight lost from APCS coal when left in air for 15 days.

$\begin{array}{crrrrr}\text { APCS } & \begin{array}{r}\text { \% Carbon } \\ \text { Coal }\end{array} & \text { \% Water } & \begin{array}{r}\text { \% weight } \\ \text { loss (V) }\end{array} & \begin{array}{r}\text { \% weight } \\ \text { gain (V) }\end{array} & \begin{array}{r}\text { \% weight } \\ \text { loss (A) }\end{array} \\ \text { BZ } & 74.05 & 32.24 & 32.6 & 7.0 & 24.8 \\ \text { WA } & 76.04 & 28.09 & 28.0 & 5.6 & 20.4 \\ \text { IL } & 80.73 & 7.97 & & 2.2 & 5.6 \\ \text { BC } & 81.32 & 4.63 & 4.7 & 2.0 & 2.2 \\ \text { PI } & 84.95 & 1.65 & 1.7 & 1.0 & 0.2 \\ \text { LS } & 85.47 & 2.43 & 2.2 & 1.4 & 1.2 \\ \text { UF } & 88.08 & 1.13 & 1.0 & 0.4 & 0.8 \\ \text { PO } & 91.81 & \mathbf{0 . 6 5} & 0.8 & 0.6 & <1.0\end{array}$


As shown in the previous table, the weight lost upon evacuation very closely approximates the total water content of the coal and is even slightly greater in most cases. It can therefore be safely assumed that water removal attained by vacuum treatment of the coals was effectively complete. The dried coal v/as observed to have a hydroscopic nature as further measurements showed that these coals all increased in weight over time when left in air to oxidize. Because the coals picked up water, it would be very difficult to differentiate between structural changes caused by oxidation and structural changes due to dehydration.

Comparison to coals oxidized in air showed that the pore structure, as determined by EPR spin probe techniques, for vacuum dried coals was similar to that of air oxidized coals. This would seem to suggest that the effects of air oxidation on coal structure can be attributed largely to dehydration. Also, a comparison of the swelling experiments run for vacuum dried, air oxidized coals and air oxidized coals in toluene with polar spin probes $\left(\mathrm{COOH}\right.$ and $\left.\mathrm{NH}_{2}\right)$, indicated that coals which were vacuum dried and then air oxidized had greater spin probe retention.

However, preliminary examination of the EPR spectra collected on the swelling of coals oxidized in the absence of water has shown significant effects upon oxidation. In general, it appears that vacuum drying coals facilitates the oxidation of coal, and that the presence of water will greatly alter the effects of coal oxidation. A more extensive study of the results obtained from coal oxidation in an $\mathrm{O}_{2}$ environment is currently underway. 


\section{STUDIES PLANNED FOR NEXT QUARTER}

The primary goal will be to complete a detailed analysis of the data collected from the swelling of coals oxidized in a moisture free environment. On the basis of these results, experimental procedure will be developed to carry out studies on the effects of short term oxidation.

\section{REFERENCES}

1. Wuu, S.K.; Kispert, L.D. Fuel 1981, 64, 1681-1686.

2. Kispert, L.D.; Cooray, L.S.; Wuu, S.K. Prepr. Pap. Am. Chem. Soc., Div. Fuel Chem. 1987, 32, 286-292.

3. Cooray, L.S.; Kispert, L.D.; Wuu, S.K. Prepr. Pap. Am. Chem. Soc., Div. Fuel Chem. 1988, 33, 32-37.

4. Goslar, J.; Kispert, L.D. Energy to Fuels 1989, 3 , 589-594.

5. Goslar, J., Cooray, L.S., Kispert, L.D. Fuel 1989, 68, 1402-1407.

6. Goslar, J., Kispert, L.D.Fuel 1990, 69, 564-569.

7. Spears, R.; Goslar, J.; Kispert, L.D. in "Techniques in Magnetic Resonance for Carbonaceous Solids," Botto, R., and Sanada, Y. Eds., ACS Symposium Series No. 229, In Press.

8. Spears, R.; Kispert, L.D.; Piekara-Sady, L. Am. Chem. Soc. Div. Fuel. Chem. Prepr. 1991, 36, 29.

9. Spears, R.; Sady, W.; Kispert, L.D. Am. Chem. Soc. Div. Fuel Chem. Prepr. 1991, $36,1277$. 
10. Spears, R.; Kispert, L.D.; Piekara-Sady, L. Fuel 1992, 71, 1003.

11. Spears, D. R.; Sady, W.; Kispert, L.D. Fuel 1992, In Press.

12. Sady, W.; Kispert, L.D.; Spears, D.R. Am. Chem. Soc. Fuel Chem. Prepr. 1992, 37, 1151. 

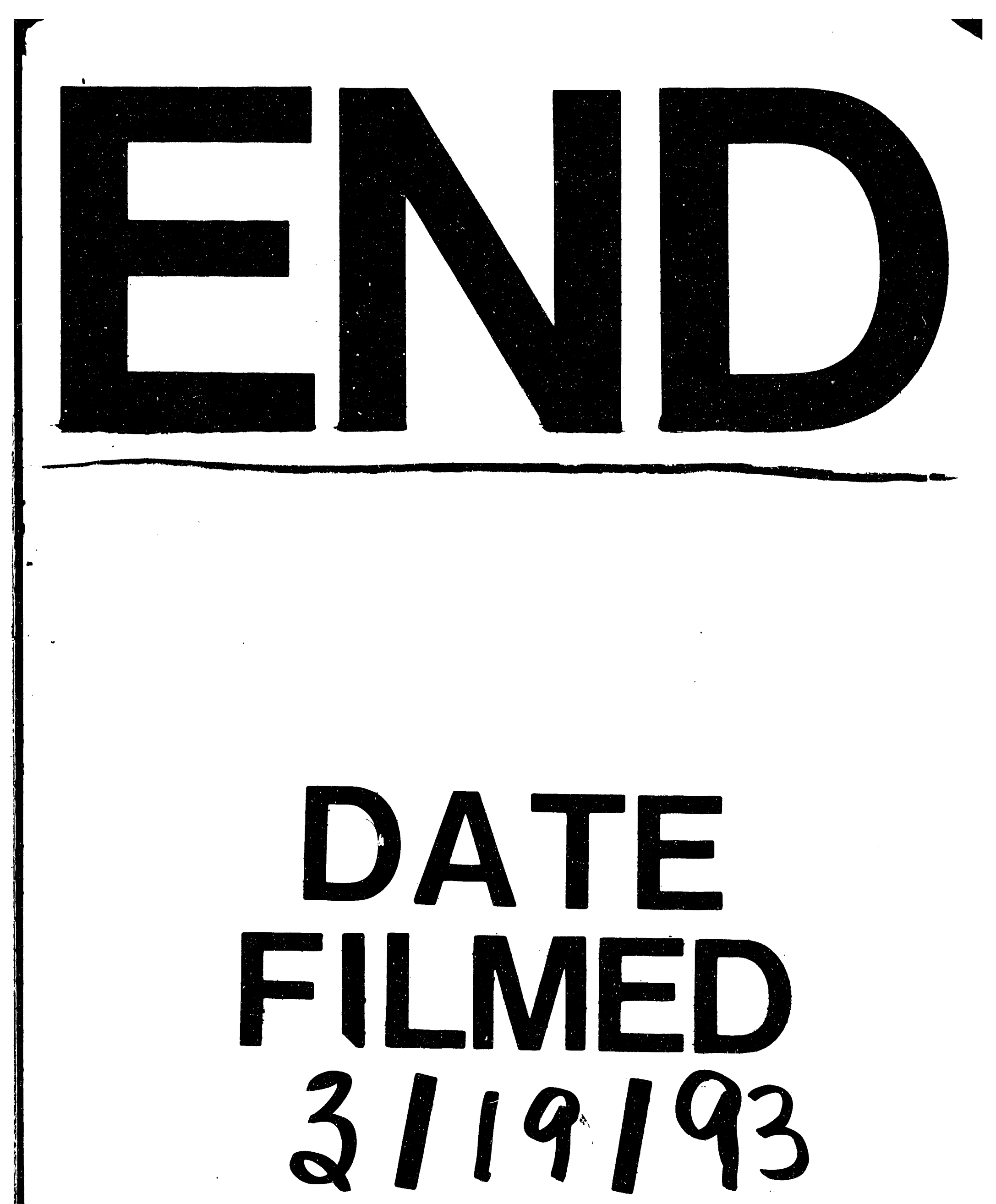
